\title{
REFUGIADOS, REINTEGRAÇÃO E MOBILIDADE INTERNA: UM OLHAR SOBRE O CASO ANGOLANO, 2002-2018
}

\author{
Refugees, reintegration and internal mobility: \\ a look at the Angolan case, 2002-2018
}

Carlos M. Lopes*

\begin{abstract}
Resumo. O objectivo desta reflexão é, para além de sistematizar as principais características associadas ao processo de retorno e de reintegração dos refugiados angolanos nos países vizinhos, procurar fazer alguma luz e identificar pistas que permitam uma melhor compreensão da articulação entre as circunstâncias envolventes do retorno e as trajectórias e lógicas de mobilidade interna dos ex-refugiados angolanos. Um eixo analítico complementar relaciona o regresso dos refugiados com as características da urbanização da sociedade angolana. Finalmente, um último eixo analítico observa a recente vaga de refugiados provenientes da RDC (2017), no contexto do conflito militar que atinge partes do país vizinho e que fez afluir a Angola cerca de 35.000 refugiados. O suporte informativo da reflexão são os dados recolhidos na literatura recentemente produzida sobre migrações no contexto angolano, a escassa informação estatística disponível, os relatórios do ACNUR-Angola e a informação publicada pelos principais órgãos da imprensa angolana.
\end{abstract}

Palavras-chave: migrações; migrações internas; refugiados; reinserção; urbanização.

\begin{abstract}
The purposes of this reflection are to systematize the main characteristics associated with the process of return and reintegration of Angolan refugees in neighbouring countries, to shed some light and identify clues that allow a better understanding of the linkage between the circumstances that surrounded the return of refugees and also the trajectories and the logic of internal mobility of former Angolan refugees. It is also a purpose of this study to relate the return of the refugees with the characteristics of the urbanization of the country. Lastly, a final analytical focus is on the recent wave of refugees from the DRC (2017), in the context of the military conflict affecting parts of the neighbouring country, which has brought about 35,000 refugees to Angola. Information relies on data collected in literature recently produced on migration in Angolan context,
\end{abstract}

* Docente e Pesquisador do Instituto Superior Politécnico de Tecnologias e Ciências (ISPTEC) Angola. CEsA-ISEG-UL. Luanda, Angola. 
the UNHCR-Angola reports, the scarce statistical information available and information published in main Angolan press.

Keywords: migration; internal migration; refugees; reintegration; urbanization.

\section{Introdução ${ }^{1}$}

Sobre migrações em Angola existem vários estudos, com linhas analíticas diferenciadas: a) a principal engloba um conjunto de trabalhos relacionados com as dinâmicas de mobilidade dos deslocados e com os aspectos relacionados com a (re)integração dos retornados e refugiados (Hansen, 1981; Marques, 2003; Human Rights Watch, 2005; Kaun, 2008; Melo, 2013; Inglês, 2017); b) alguns trabalhos que analisam a relação entre migrações e desenvolvimento (Nyberg-Sorensen, Engberg-Pedersen, 2002; Lopes 2013a); c) um leque diversificado de abordagens que analisam, entre outros temas, o modo como a condição de migrante afecta a vida dos habitantes da periferia dos centros urbanos (Robson, Roque, 2001), a relação entre fluxos migratórios, identidade e estado pré-colonial (Luansi, 2003), a diáspora angolana em Lisboa (Øien, 2007; Ferreira, Lopes, Mortágua, 2008), o impacto das remessas dos emigrantes angolanos na África do Sul e em Portugal sobre as condições de vida das comunidades beneficiárias (OIM, 2010), as articulações entre a migração interna, a urbanização e saúde (Lopes, Rodrigues, Simas, 2013), a gestão das bases de dados sobre migrações (Lopes, 2013b), a relação entre as políticas migratórias e os refugiados (Muller, 2016) ou a dicotomia de efeitos entre a imigração legal e imigração ilegal (Milagres, Santos, 2018).

Essa ampla literatura, em termos gerais, confirma como um dos efeitos mais expressivos do conflito militar prolongado em Angola foi a deslocação massiva das populações para as áreas de segurança nos centros urbanos de maior dimensão, nomeadamente Luanda, bem como para os países limítrofes.

A transição e a consolidação do processo de paz, com as transformações socioeconómicas subsequentes, após 2002, transformaram o país de "exportador" em "importador" de refugiados. Este processo tem vindo a desenrolar-se em paralelo com uma mudança na natureza e na dinâmica dos fluxos migratórios internos, que permanecem intensos e ainda pouco conhecidos.

O objectivo deste artigo é apresentar as principais dinâmicas migratórias internas em Angola, no período entre 2002 e 2018, com um foco particular nas inter-relações entre a mobilidade interna registada no pós-guerra, o regresso e reintegração dos refugiados angolanos nos países vizinhos, e a variável mais

\footnotetext{
1 O presente texto foi redigido em língua portuguesa não contemplando o Acordo Ortográfico, uma vez que Angola dele não foi signatária.
} 
recente, associada à presença em território angolano de refugiados do conflito militar que ocorre na República Democrática do Congo.

O artigo inicia-se com uma contextualização política, económica e social do período em análise, a que se sucede uma contextualização das dinâmicas migratórias e do processo de mudança que as tem caracterizado. No ponto seguinte, aborda-se o regresso a Angola dos refugiados angolanos nos países vizinhos, a que se segue uma análise mais detalhada das migrações internas angolanas, com base na informação estatística gerada pelo Inquérito Integrado sobre o Bem-Estar da População, 2008-09. Uma breve análise da relação entre as dinâmicas de mobilidade interna e o processo de urbanização acelerada que se intensificou no pós-guerra, bem como uma também breve referência à problemática recente de vagas de refugiados provenientes da R.D. Congo, precedem a conclusão, onde, para além da síntese da informação mais relevante, se reflecte sobre a necessidade e a importância de políticas públicas orientadas para a gestão dos fluxos migratórios.

\section{Contexto Geral}

Com o final da guerra civil de 27 anos, em 2002, Angola experenciou uma fase de rápido crescimento económico, graças ao desempenho dos sectores petrolífero e diamantífero. A economia angolana registou elevadas taxas de crescimento ao longo dos últimos 16 anos, em resultado, fundamentalmente, do estabelecimento de um clima de paz no país, do desempenho do sector petrolífero - que representou, entre 2013 e 2016, 95\% das exportações totais e $70 \%$ das receitas fiscais do Governo (CEIC, 2017) - e ainda da eficácia da estratégia de estabilização económica posta em prática pelas autoridades angolanas. Este período apresentou duas fases distintas: um rápido crescimento económico (alavancado nos sectores petrolífero e diamantífero) entre 2001 e 2010 (11,1\% - The Economist, 2011) e, após a crise do "subprime norteamericano" que também afectou o país, a retomada crescimento económico entre 2010 e 2013; uma fase de declínio após 2014 como consequência da queda drástica do preço do barril de petróleo, registada a partir de 2014, que teve como efeito a contracção da actividade económica, seja pelo efeito directo seja devido à diminuição das despesas públicas e privadas, decorrente da redução dos rendimentos na economia.

Os indicadores socioeconómicos demonstram alguns avanços nos últimos 16 anos, mas muitos desafios permanecem. O país, que está comprometido num processo de graduação para País de Rendimento Médio em 2021, apresenta ainda indicadores contraditórios: o Índice de Desenvolvimento Humano de Angola foi de 0.533 em 2016 (150a posição entre 188 países quando ajustado pela desigualdade, o IDH de Angola perde $37 \%$ e é reduzido para 0,336); a distribuição do rendimento permanece bastante desigual (taxa 
de pobreza nacional de Angola é de 36,6\%, sendo 58,3\% nas áreas rurais e $18,7 \%$ nas áreas urbanas (2008) - coeficiente de Gini foi, em média, de 42,7 no período 2010-2015). Angola produz muito pouco internamente e importa quase tudo (economia fortemente dependente do petróleo aproximadamente 1/3 do PIB de Angola e mais de 95\% das exportações, o que torna os níveis de vida extremamente caros, em especial na capital Luanda) e permanece muito vulnerável aos desastres naturais e mudanças climáticas, particularmente inundações e secas que ameaçam os ecossistemas vitais e recursos biológicos.

Embora o final da guerra tenha removido o principal factor causador de problemas, a situação de paz traz para o primeiro plano uma série de outros problemas subjacentes que ainda precisam ser resolvidos. No âmbito de análise que esta abordagem comporta, destacam-se os desafios que o rápido crescimento populacional e a pressão dos fluxos internos colocam em termos de urbanização, e a consolidação dos processos de reinserção e integração dos ex-refugiados angolanos nos países limítrofes, no quadro mais geral do combate à pobreza urbana e rural.

A população em 2010 estava estimada em cerca de 19 milhões de habitantes e era particularmente jovem, com 45\% da população tendo menos de 15 anos de idade (PNUD, 2009). Os dados definitivos do Censo 2014 reportaram uma população de 25,7 milhões de habitantes, desigualmente distribuídos no território e maioritariamente jovens (65,5\% tinha em 2014 menos de 25 anos de idade). O país experienciou também uma rápida urbanização. Mais de metade da população (58,5 \% estimado para 2010) vivia em área urbanas, com alta concentração na capital Luanda e periferias (OIM, 2010), onde pessoas de outras regiões de Angola se instalaram, uma vez que eram consideradas locais mais seguros e com melhores oportunidades económicas. Segundo os dados definitivos do Censo 2014, 62,6\% do efectivo populacional angolano é urbano enquanto $37,47 \%$ reside nas áreas rurais. Luanda concentrava 6,9 milhões de pessoas (mais de um quarto da população do País) e o conjunto das 7 principais províncias (para além de Luanda, Huíla, Benguela, Huambo, Cuanza Sul, Uíge e Bié) correspondia a aproximadamente $72 \%$, o que evidencia o enviesamento urbano e a assimetria entre o litoral e $\mathrm{o}$ interior.

Elevadas taxas de fertilidade (5,9 crianças por mulher, em média no período 2010-2015), determinam elevadas taxas de crescimento natural e sustentam projecções que apontam para que, em 2017, existissem mais 2,7 milhões de angolanos, totalizando 28,4 milhões de habitantes (INE, 2016 base: taxa média de crescimento natural da população de $3 \%$ ). 


\section{O contexto migratório}

Durante o conflito armado pós-independência (1975-2002), Angola foi caracterizada sobretudo pela migração interna do meio rural para o meio urbano (especialmente para a capital Luanda), por deslocações internas e por fluxos de saída transfronteiriços de refugiados.

As tendências e padrões de migração encontram-se em transição acelerada, com consequências nem sempre fáceis de conhecer, compreender, avaliar e gerir para quem administra e participa, aos diferentes níveis, nos processos de desenvolvimento.

No caso de Angola, o panorama dos fluxos migratórios tem contornos similares aos da generalidade dos países africanos, mas apresenta aspectos particulares: o contexto de crescimento acelerado da economia do país até 2014, impulsionou as dinâmicas das migrações internas, com destaque para a mobilidade laboral e estudantil, que se interpenetraram com fluxos mistos, com o fenómeno dos refugiados e dos requerentes de asilo, com tráfico de pessoas e com a intensificação das relações com a diáspora.

No plano das migrações internas, continuaram a registar-se fluxos e ritmos elevados de mobilidade, apesar do final do conflito militar em 2002. À deslocação interna forçada em direcção aos principais centros urbanos, e nomeadamente à capital do país, e aos países vizinhos, sucedeu-se a continuidade da mobilidade interna, agora motivada pela procura de oportunidades económicas e do acesso aos centros de decisão, aos serviços socias básicos e a mecanismos de mobilidade social, bem como por episódios cíclicos relacionados com fenómenos naturais extremos, como secas e cheias (Lopes, 2013a).

Acresce que o regresso de parte significativa da população refugiada nos países limítrofes se veio a constituir também como factor de mobilidade interna, uma vez que parte dos migrantes retornados, após a reinstalação nos locais de origem, aí não permaneceram. O Plano Estratégico da Organização Internacional para as Migrações-Angola para o biénio 2009-2010 (Lopes, 2013b) referia que após o final da guerra (2002), o Processo de Repatriamento Voluntário permitiu o regresso de mais de 400.000 angolanos refugiados nos países vizinhos (Zâmbia, RDC e Namíbia). A problemática das migrações de retorno continuou na ordem do dia no contexto angolano, uma vez que o retorno ao país continuou a ser uma opção de inúmeros angolanos instalados na Zâmbia, na Namíbia e na República Democrática do Congo. O já referido documento da OIM-Angola sublinha o peso elevado das sequelas do conflito militar nos processos de mobilidade dos angolanos: a par de um insucesso relativo das políticas e programas de reintegração, a escassez de opções e de oportunidades nas zonas rurais, fortemente desestruturadas pelo impacto 
do conflito militar prolongado, induziu ritmos elevados de migração para os centros urbanos e, particularmente, para a capital, Luanda. Jovens e mulheres, mas também retornados (ex-militares, refugiados, população deslocada internamente) engrossaram estes fluxos migratórios que colocaram sob uma pressão intensa os equipamentos e serviços sociais urbanos, como revelou um estudo realizado pelo Observatório ACP das Migrações (Lopes, Rodrigues, Simas, 2013).

Entretanto, a reabilitação e o crescimento da economia angolana no contexto regional e internacional induziram uma inversão nos fluxos migratórios internacionais, passando o país a atrair imigrantes, qualificados mas também em número crescente com reduzidas qualificações, e a registar-se o regresso progressivo de angolanos da diáspora. Em paralelo, registou-se também um significativo aumento do potencial de atracção do país em relação aos migrantes irregulares. Por outro lado, o país transformou-se em receptor de refugiados e de requerentes de asilo (Lopes, 2013a).

Resultaram destas dinâmicas de transição e mudança dos fluxos migratórios que envolvem o Estado e cidadãos angolanos, efeitos diversificados e que interagem reciprocamente, provocando impactos diferenciados na economia e na sociedade angolana, com repercussões mais expressivas nos domínios da urbanização não planificada, em dificuldades no acesso aos serviços sociais básicos e à protecção social, no aumento de participação dos migrantes em actividades informais, no aumento de oportunidades de exploração e de abusos sobre os migrantes laborais e irregulares, no aumento da precariedade, da vulnerabilidade e da pobreza e no crescimento das ameaças à segurança humana e ambiental (Lopes, 2013a).

E os impactos supracitados, cada um por si, e em conjunto, têm gerado implicações substanciais no que respeita à estabilidade política e à definição das políticas que possibilitam a sua gestão.

\section{0 regresso dos ex-refugiados}

Um dos efeitos mais expressivos do conflito militar prolongado em Angola foi a deslocação massiva das populações, para as áreas de segurança nos centros urbanos de maior dimensão e, em particular para a capital, bem como para os países limítrofes.

De acordo com o Alto Comissariado das Nações Unidas para os Refugiados (ACNUR), o conflito armado, com a guerra colonial e a guerra civil em Angola, entre 1961 e 2002, provocou a deslocação forçada de quatro milhões de pessoas e o exílio de outras $600 \mathrm{mil}^{2}$.

\footnotetext{
2 Cf. <http://observador.pt/2014/06/20/mais-de-meio-milhao-de-refugiados-regressaram-angola-
} desde-o-fim-da-guerra/ $>$. 
O Programa de Repatriamento Voluntário (2003-2007) conduzido em parceria pela OIM, o Alto Comissariado das Nações Unidas para os Refugiados (UNHCR) e o Ministério de Assistência e Reinserção Social (MINARS) visou o repatriamento de cerca de 420.000 refugiados. Depois desta operação, que terminou em Março de 2007, cerca de 146.814 angolanos optaram por permanecer nos países de asilo, na condição de refugiados, dos quais 27.073 na Zâmbia, 111.589 na República Democrática do Congo (RDC), 5.600 na Namíbia e 2.652 no Congo Brazzaville (ACNUR, 2008).

Entre Junho de 2011 e Junho de 2012 verificou-se o regresso de 23.343 cidadãos angolanos, no quadro de um programa de repatriamento voluntário e organizado, aprovado em 2010 pelo executivo angolano e implementado em parceria com o Alto Comissariado das Nações Unidas para os Refugiados (ACNUR), de um total de cerca de 53 mil refugiados angolanos que pretendiam regressar a partir do Botsuana, do Congo-Brazzaville, da República Democrática do Congo, da Namíbia e da Zâmbia (ACNUR, 2011).

Declarações públicas do responsável do departamento de Refugiados do Ministério da Assistência e Reinserção Social de Angola (MINARS), no âmbito do dia internacional do Refugiado, sugeriam que "de 2002 a 2013 já tinham regressado mais de 500 mil angolanos que se encontravam na condição de refugiados". Ainda segundo a mesma fonte, o Executivo angolano previa o regresso voluntário dos últimos 26 mil refugiados que manifestaram essa pretensão, provenientes nomeadamente da República Democrática do Congo e da Zâmbia ${ }^{3}$.

Enquanto as autoridades angolanas avaliaram o processo como um sucesso apesar das dificuldades, um relatório de avaliação publicado em 2008 pelo ACNUR inventariou as seguintes dificuldades no processo de reintegração dos retornados: baixos níveis de segurança alimentar para os repatriados e as suas comunidades; acesso limitado a empregos, a actividades geradoras de rendimento e a serviços públicos; movimentos significativos de repatriados das zonas rurais para zonas urbanas; sérios constrangimentos para obter documentos de identidade nacionais e validar as qualificações académicas e profissionais obtidas no exterior.

Através da Unidade Técnica de Coordenação da Ajuda Humanitária (UTCAH), o MINARS esteve envolvido nas diferentes etapas do processo de repatriamento dos angolanos refugiados nos países vizinhos, competindo-lhe acompanhar e apoiar o processo de reinstalação e reintegração dos angolanos retornados/repatriados. Para além do Programa de Reintegração Social nas áreas de retorno, o MINARS implementou um Projecto de Assistência aos

\footnotetext{
3 Cf. <http://observador.pt/2014/06/20/mais-de-meio-milhao-de-refugiados-regressaram-angoladesde-o-fim-da-guerra/ $>$.
} 
refugiados estrangeiros em território angolano, com o objectivo de os integrar em comunidades de acolhimento.

As Normas sobre o Reassentamento das Populações Deslocadas, de 2001, publicadas pelo Governo de Angola (e regulamentadas em 2002), visaram sobretudo as populações afectadas diretamente pelo conflito logo após o seu término, reconhecendo a importância de o seu reassentamento ser voluntário e implicar o seu envolvimento nos procedimentos para a relocalização, identificação e distribuição de terras. Embora se tenha de certa forma diluído este processo no contexto nacional, permanecem muitos dos efeitos tanto das próprias deslocações durante a guerra como das políticas e acções de reinserção e reintegração das populações deslocadas. De entre estes, destaca-se a elevada concentração em meio urbano, sobretudo no litoral do país.

Um estudo sobre a integração dos angolanos que regressaram recentemente (Melo, 2013) visou analisar a migração de retorno, as estratégias de reintegração e as relações entre estes fluxos migratórios e o desenvolvimento humano. Das principais conclusões, destacam-se as seguintes ideias: os resultados mostram que a maioria dos migrantes inquiridos regressou do país vizinho mais próximo da sua residência actual; parte significativa dos inquiridos revelou encontrar-se actualmente em melhor ou igual situação socioeconómica em relação às condições de que dispunha nos países de acolhimento, sendo que a maioria se manifestou satisfeita com o nível de acesso aos serviços sociais disponíveis; uma elevada percentagem dos entrevistados referiu explicitamente a assistência do Governo de Angola no processo de retorno, sendo reclamada maior atenção ao caso específico dos retornados altamente qualificados. O estudo concluiu que são necessários estudos adicionais de avaliação das necessidades que sirvam de base à elaboração de planos e politícas de reintegração mais adequadas e eficazes e evidenciou a insuficiência no acesso à terra e a serviços sociais básicos bem como os problemas decorrentes das barreiras culturais como ameaças ao processo de reintegração, induzindo sentimentos de marginalização entre alguns grupos de ex-refugiados.

O estudo em referência sublinhou ainda que os destinos iniciais da vasta maioria dos regressados foram as províncias que ficam mais próximas das fronteiras com os países onde antes viviam com o estatuto de refugiado e que uma percentagem considerável dos ex-refugiados regressados se deslocaram posteriormente, para outras áreas ou províncias (tipicamente, para cidades caracterizadas pela existência de oportunidades económicas mais favoráveis), com a esperança de assim melhorarem as suas condições de vida. 


\section{Migrações Internas}

Com a independência do país em 1975, as migrações internas aumentaram exponencialmente devido à eclosão da guerra civil no país, que afectou sobretudo as áreas rurais. Por um lado, a guerra implicou a deslocação interna de um elevado número de militares, ao mesmo tempo que impediu a deslocação de um número significativo de pessoas que foram mantidas em cativeiro pelas forças beligerantes. Por outro lado, a guerra civil angolana forçou um contingente populacional numeroso a refugiar-se nas cidades tidas como refúgio para a guerra que se desenrolou sobretudo no meio rural. Em todas as cidades, mas sobretudo em Luanda, assistiu-se durante várias décadas a um crescimento contínuo e elevado da população. Na altura do conflito, o número de deslocados internos angolanos foi estimado em 3,8 milhões (BAD/ OECD, 2008).

Após o final da guerra, em 2002, o retorno às áreas rurais desta população não foi significativo e o ritmo de crescimento das cidades manteve-se elevado. Continuaram a ser causas principais deste crescimento a procura de melhores condições de vida, num contexto pós-guerra de elevada pobreza e precariedade. Porém, os padrões da migração interna tornaram-se mais complexos (Lopes, Rodrigues, Simas, 2013). Em Luanda e noutros centros urbanos, as populações também estão em movimento e vão ocorrendo com maior frequência fenómenos de migração temporária, com carácter interprovincial.

As fontes de dados sobre migrantes incluem geralmente censos relativos à população e à habitação, registos populacionais, registos administrativos, estatísticas fronteiriças e aduaneiras e inquéritos por amostragem (agregado familiar). No caso de Angola, conjuga-se um número insuficiente de fontes de dados fiáveis com lacunas de dados significativas. O anterior Censo angolano datava de há cerca de 40 anos, tendo sido realizado em 2015 um Recenseamento Geral da População e Habitação. Em 2008/09 foi realizado pelo INE (2010), com apoio do Banco Mundial e da Unicef, um inquérito por amostragem (Inquérito Integrado sobre o Bem-Estar da População 2008-09, IBEP), contendo um número limitado de questões sobre migração e uma amostra de migrantes reduzida, como resultado da dificuldade em encontrar migrantes em estruturas de amostragem regulares e do facto de que a medição dos fluxos requer dimensões de amostragem suficientemente grandes.

Tratou-se do primeiro inquérito realizado após a independência do país e após o término do conflito civil, em todo o território nacional, cobrindo de forma representativa tanto áreas urbanas como rurais do país. O IBEP 2008-09 considerou quatro questões para avaliar o fenómeno migratório: lugar de residência actual, lugar de nascimento, lugar de residência antes de 1975 e 
lugar de residência depois de 2002. No IBEP 2008-09 o foco da análise recaiu sobre a migração definitiva, tendo sido ignorados movimentos de população temporários ou sazonais importantes, que são também determinantes cruciais da estrutura e composição da população. A recolha de informação efectuada alicerçou-se sobre uma grelha analítica que identificou, em termos migratórios, quatro momentos históricos cruciais: (i) antes da independência nacional em 1975; (ii) entre a independência e as primeiras eleições gerais em 1992; (iii) após as eleições em 1992 e antes do acordo de paz em 2002, e (iv) após o acordo de paz.

As estimativas de migração interna resultantes do IBEP 2008-09 indicam que $12,6 \%$ da população angolana migrou da sua província de nascimento e que $19,7 \%$ se mudou de áreas rurais para urbanas enquanto 4,1\% terá realizado o percurso inverso movimentando-se de áreas urbanas para áreas rurais. Com uma taxa de migração total de 13,4\%, conclui-se que, à data do inquérito, cerca de $1 \%$ da população era constituída por imigrantes de países estrangeiros

Uma conclusão relevante é a de que a taxa de migração interna variou entre províncias, detendo Luanda a taxa mais elevada (30,5\%), em sintonia com o nível de disponibilidade de serviços básicos em Luanda relativamente às outras províncias, o nível de crescimento urbano e a percepção que predominou durante vários anos de que existem em Luanda mais oportunidades de geração de rendimentos.

O IBEP 2008-2009 analisou também tendências de migração entre 1975 e 2002. Em termos globais, à escala do país, o período entre 1992 e os acordos de Paz de 2002 concentrou 35,2\% das respostas. Entre 1975 e 1992 registaram-se $33,1 \%$ das respostas, $22,6 \%$ após o acordo de paz e apenas 9,1\% antes de 1975 .

A guerra, pelos efeitos que gerou, directos e indirectos, foi o principal factor que motivou a mudança de residência da grande maioria da população migrante. No que se refere às causas e motivações da migração, tanto nas zonas rurais como urbanas, o reencontro familiar foi a principal razão de migração para 50,6\% dos migrantes rurais e 47,3\% dos urbanos. A guerra, que está também associada ao reencontro familiar $(47,8 \%)$, surgiu como o segundo principal factor que influenciou as decisões de migração $(25,4 \%)$

O factor guerra surge particularmente presente nas respostas dos migrantes da maioria das províncias: Huíla (35,6\%), Kwanza Norte (33\%), Luanda (28,3\%), Kuando Kubango (28,2\%), Kwanza Sul (26,8\%), Benguela (25,3\%), Lunda Norte e Huambo (17,1\% em cada), Namibe $(16,6 \%)$ e Bié $(15,5 \%)$.

Em três das províncias, o fator reassentamento assumiu um peso relativo mais expressivo nas respostas obtidas: Kuando Kubango (26,5\%), Zaire (20,1\%) 
e Moxico (15,6\%). Os factores de natureza económica e social (procura de trabalho, transferências no quadro da actividade profissional e procura de estudos) apresentaram menor influência sobre a decisão de mudança permanente da província de origem.

As razões para a migração também variaram de acordo com o período de referência. Cerca de 39\% dos movimentos migratórios, no período compreendido entre a independência em 1975 e as primeiras eleições gerais em 1992, foram motivados pela guerra, mas um número igual de migrantes movimentou-se por motivos de reencontro familiar durante o mesmo período. No entanto, a proporção de migrantes que procuravam o reencontro familiar atingiu o pico de 59\% na sequência do acordo de paz de 2002, período em que também se registou a maior proporção de crianças em idade escolar (5-14 anos de idade) que migraram à procura de oportunidades de educação.

Os dados recolhidos indicaram as províncias de Luanda (30,5\%), Namibe $(19,8 \%)$ e Cunene $(16,4 \%)$ coma as que apresentaram indicadores mais expressivos no que se refere à migração interna. Huambo (2,7\%), Uíge (2\%) e Kwanza Sul (1,7\%) são as que registaram indicadores mais reduzidos. Registe-se, no entanto, que esta leitura dos dados deve ser relativizada, uma vez que em províncias como o Namibe ou o Cunene o indicador de migração interna, comparativamente a Luanda, pode surgir sobreavaliado, em função da reduzida população de cada uma daquelas duas províncias.

Os dados apurados revelaram que os padrões de migração interna em Angola não são explicados apenas pelas diferenças de oportunidades económicas e sociais entre as províncias, apresentando Benguela e Huíla, províncias de maior referência económica, taxas inferiores às províncias fronteiriças como Cunene, Lunda Sul e Zaire. Estes dados deverão também ser referidos com a prudência exigida pelo conhecimento que se tem de que muitos dos migrantes internos presentes nestas províncias fronteiriças terão provindo do exterior do país. Existem, portanto, outras causas para migração interna em Angola que só podem ser identificadas em estudos mais profundos de dinâmica da população

Um estudo sobre as articulações entre a migração interna, a urbanização e a saúde em Angola, promovido pelo Observatório ACP das Migrações (Lopes, Rodrigues, Simas, 2013), constatou, para além das migrações campo-cidade e entre centros urbanos, a existência, em algumas regiões, de fluxos migratórios temporários com diferentes características e com alguma expressão. Por outro lado, permitiu também validar algumas hipóteses constantes da literatura previamente existente, no que se refere às características do processo de assentamento e fixação das populações migrantes. Relativamente ao acesso aos serviços de saúde, as principais constatações da pesquisa apontaram para que não existam grandes diferenças entre migrantes e não-migrantes e sugerem 
que a mobilidade interna em Angola relacionada com a saúde é determinada sobretudo pela procura de melhores condições de acesso aos serviços.

As principais motivações para migrar no contexto angolano inventariadas pelo estudo foram: a) de ordem socioeconómica; b) por motivos políticos ou de natureza infra-estrutural; c) relacionadas com factores climáticos ou ambientais; d) relacionadas com questões de segurança e de ordem sóciocultural ou étnica. Apurou-se que essas motivações determinavam diferentes tipos de mobilidade interna, nomeadamente: migração laboral subordinada ou independente, formal ou informal, fluxos migratórios temporários e pendulares, migração estudantil em direcção aos principais centros educativos do país, deslocações internas forçadas, mobilidade interna associada à reinserção e reintegração de ex-refugiados, mobilidade interna motivada por melhores condições de acesso a serviços básicos, ligada à constituição de família e ao casamento ou orientado ao reagrupamento familiar.

\section{Urbanização}

Em Angola, para além das tendências de urbanização colonial motivada por uma (relativa) necessidade de mão-de-obra associada à indústria e aos serviços, foi sem dúvida depois da independência que se registou a maior concentração de população nos centros urbanos.

A causa principal para o aumento exponencial da urbanização em Angola durante os 39 anos desde a independência foi a guerra civil, a que se vieram acrescentar, após 2002, os efeitos associados à mobilidade humana socioeconómica e cultural, de carácter voluntário. A já referida concentração de cerca de $72 \%$ da população angolana em 7 províncias (INE, 2014) reflecte a continuidade do crescimento da Angola urbana, uma vez que nessas províncias se localizam os principais centros urbanos do país: Luanda, Lubango, Benguela, Huambo e Lobito.

A reduzida taxa de actividade (relação entre a população economicamente activa e a população em idade activa de 15 e mais anos) fixada em 53\%, a nível nacional (Censo, 2014) e uma taxa de desemprego, a nível nacional, de $24 \%$, atingindo mais severamente os grupos etários mais jovens - em cada dois jovens um estava desempregado - são alguns dos factores com impacto directo negativo sobre as cidades, com muitos migrantes a não serem absorvidos pelas economias urbanas (o que se repercute na proliferação das actividades informais), com a proliferação e alastramento das áreas de assentamento não planeado nas periferias dos centros urbanos (musseques) e com a consequente pressão sobre as infra-estruturas sociais, especialmente escolas, unidades de oferta de serviços de saúde, habitação e crescentes dificuldades de abastecimento urbano de água e saneamento, com implicações sérias para a higiene e a saúde. 
Estes problemas acentuam-se com o acelerado crescimento populacional das principais áreas urbanas, uma vez que a projecções para 2018 do INE estimavam, por exemplo, em 2018, efectivos populacionais de 7.774.168 habitantes para Luanda, de 1.599.361 habitantes no eixo BenguelaCatumbela-Lobito e de 1.153.327 habitantes na área urbana do Huambo (Atlas da Urbanização de Angola) ${ }^{4}$.

\section{Os refugiados da RDC}

Nos últimos meses, a partir de Março de 2017, o país confrontou-se com a entrada no país de refugiados oriundos da região do Kasai na RDC. Cerca de 36.094 refugiados foram assistidos, na Província da Lunda Norte, no quadro da resposta de emergência coordenada entre o Executivo, o ACNUR e organizações da sociedade civil, com fundos mobilizados também de outros doadores. Foi efectuado o registo biométrico dos refugiados, que foram instalados em campos de refugiados ou que se encontram inseridos nas comunidades locais.

A realidade actual do país situava-se em 31/5/2018 em 68.348 refugiados e requerentes de asilo de várias nacionalidades, maioritariamente concentrados nas províncias da Lunda Norte, Luanda e Huambo. Para além dos refugiados da RDC, encontram-se também nacionais de outros países, como, por exemplo, a Costa do Marfim, Mauritânia, Sudão, Serra Leoa e Ruanda 5 .

A não implementação da Lei no 10/15, de 17 de Junho, relativa ao Direito de Asilo e Estatuto de Refugiado, bem como a não continuidade do registo dos refugiados que esteve em curso, constituem factores adicionais de incremento dos riscos e de vulnerabilidade desses migrantes, que acrescem aos problemas relacionados com as detenções por falta de documentação e aos bloqueios no acesso à saúde e educação.

\section{Conclusão}

O processo de repatriamento voluntário, desenvolvido pelo Governo de Angola, em articulação com diversas organizações internacionais e não-governamentais, mobilizou um vasto conjunto de intervenções (programas, políticas e medidas de reinserção social) que abrangeram ex-refugiados e deslocados internos.

Apesar do êxito relativo que constituiu, o processo de repatriamento e reintegração não resolveu várias questões colaterais. Como sublinha Melo (2013), entre elas podem enunciar-se, pela sua importância, questões como o acesso à terra e/ou a uma habitação condigna, a possibilidade de

\footnotetext{
${ }^{4}$ Cf. <http://onuangola.org/agencias/unhabitat/atlas/>

5 Cf. <https://data2.unhcr.org/en/country/ago $>$.
} 
adopção de estratégias de subsistência viáveis, a promoção da coexistência harmoniosa entre as comunidades de acolhimento e os migrantes regressados e a mobilização das competências específicas dos migrantes regressados no contexto do desenvolvimento económico e humano de Angola.

A transição e a consolidação do processo de paz, com as transformações socioeconómicas subsequentes, após 2002, transformaram o país de "exportador" em "importador" de refugiados. Este processo tem vindo a desenrolar-se em paralelo com uma mudança na natureza e na dinâmica dos fluxos migratórios internos, que permanecem intensos e ainda pouco conhecidos.

Se parte desses fluxos ainda tem relação com as dinâmicas de mobilidade dos ex-refugiados, uma vez que parte dos migrantes retornados, após a reinstalação nos locais de origem, aí não tem permanecido, em grande medida os actuais movimentos internos de população em Angola explicam-se em função da concentração/difusão dos centros de oportunidades económicas, de atractividade laboral e estudantil e de procura de serviços que o contexto de crescimento económico tem gerado, bem como por episódios cíclicos relacionados com fenómenos naturais extremos, como secas e cheias (2016 e 2017, nas províncias do Sul). Fenómeno mais recente são vagas de refugiados da RDC a partir de Março de 2017.

Esta forte dinâmica migratória tem-se processado de forma não planeada e a sua gestão, fundamentalmente orientada para a questão da soberania nacional, tem assumido um carácter pontual no âmbito da intervenção governativa limitando significativamente o seu potencial de impacto positivo no desenvolvimento e na sociedade. Não há ainda uma visão do potencial positivo da migração para o desenvolvimento e a gestão das migrações tem sido tratada como residual no contexto da intervenção governamental (o que tem limitado substancialmente o seu potencial de impacto positivo no desenvolvimento e na sociedade).

O conhecimento da natureza, das características e das tendências dos fluxos migratórios que envolvem o Estado e os cidadãos angolanos é um factor fundamental para que possam ser formuladas políticas públicas adequadas e com probabilidade de sucesso nos diversos domínios, nomeadamente na redução da pobreza e das desigualdades sociais. A integração da variável "migrações" como input e prioridade na intervenção política (maximizar impactos positivos e minimizar custos e externalidades negativas) implica: a necessidade de um conhecimento extensivo e aprofundado dos fluxos migratórios que envolvem o Estado e os cidadãos angolanos bem como dos seus impactos nos processos de desenvolvimento local, provincial e nacional; a criação de mecanismos que permitam gerar, analisar, gerir e partilhar os dados sobre migrações, não apenas 
em sede das instituições governamentais, directa e indirectamente interessadas, mas também com os outros parceiros para o desenvolvimento; e finalmente, a necessidade de harmonizar os procedimentos de colecta e tratamento dos dados sobre as migrações com as normas definidas pela SADC, numa lógica de contribuição para o aprofundamento da integração regional.

\section{Referências bibliográficas}

ACNUR. Avaliação do Programa de Reintegração de Refugiados do ACNUR em Angola. Geneva: ACNUR, 2008.

ACNUR. Angola. UNHCR Global Report 2010. 2011. Disponível em: <http:// www.unhcr.org/4dfdbf4cb.html>.

BAD/OCDE. African Economic Outlook 2007-2008. 2008.

CEIC-UCAN. Relatório Económico de Angola, 2016. Luanda, 2017.

FERREIRA, Eduardo; LOPES, Carlos M.; MORTÁGUA, Mária João. Diáspora angolana em Portugal: caminhos de retorno. Cascais: Princípia Editora, 2008.

HANSEN, Art. Refugee Dynamics: Angolans in Zambia 1966 to 1972. International Migration Review, v. 15, n.1/2, p. 175-194, 1981.

HUMAN RIGHTS WATCH. Coming Home: Return and Reintegration in Angola. Human Rights Watch, v. 7, n. 2, 2005.

INGLÊS, Paulo. Angola é a nossa casa. Reintegração de retornados angolanos no Uíge vindos da República Democrática do Congo. Brasília: CSEM - Centro Scalabriniano de Estudos Migratórios, 2017.

INSTITUTO NACIONAL DE ESTATÍSTICA - INE. Inquérito Integrado sobre o BemEstar da População, 2008-09. Luanda, 2010.

INSTITUTO NACIONAL DE ESTATÍSTICA - INE. Resultados definitivos do Recenseamento Geral da População e da Habitação de Angola. Luanda, 2014.

INSTITUTO NACIONAL DE ESTATíSTICA - INE. Projecção da População de Angola 2014-2050. Luanda, 2016.

KAUN, Alexandra. When the Displaced Return: Challenges to 'Reintegration' in Angola. New Issues in Refugee Research. Research Paper No. 152. Washington D.C.: Office of Refugee and Asylum, USCIS, and UNHCR Policy Development and Evaluation Service, 2008.

LOPES, Carlos M. Tema de Reflexão: o Impacto da Migração para o Desenvolvimento, Desafios e Oportunidades para Angola. Agenda Global de Desenvolvimento pós 2015, OIM, 2013a.

LOPES, Carlos M. Reforçar a gestão de dados sobre as migrações em Angola: Avaliação e recomendações. Observatório ACP das Migrações/OIM, 2013 b.

LOPES, Carlos M.; RODRIGUES, Cristina; SIMAS, Gabriela. Migração Interna, Urbanização e Saúde em Angola. Bruxelas: Observatório ACP para as Migrações, 2013. 
LUANSI, Lukonde. Angola: Movimentos migratórios e Estados precoloniais Identidade nacional e autonomia regional. International symposium Angola on the Move: Transport Routes, Communication and History, Berlin, 24-26 September, 2003.

MARQUES, Nadejda. Struggling through Peace: Return and Resettlement in Angola. Human Rights Watch, Africa Division, v. 15, n. 16, p. 1-33, 2003.

MELO, André. Regresso a uma vida melhor: A integração dos ex-refugiados angolanos após o seu regresso a Angola. Bruxelas: Observatório ACP das Migrações, 2013.

MILAGRES, Simão; SANTOS, Lutina. Fluxos migratórios em Angola - novos contextos e desafios. Luanda: Mayamba Editora, 2018.

MULLER, Paulo. Situation and context: migratory policies and interactions with refugees in northern Angola. REMHU, Revista Interdisciplinar de Mobilidade Humana, Brasília, v. 24, n. 47, p. 175-193, 2016.

NYBERG-SORENSEN. Ninna; ENGBERG-PEDERSEN, Poul. The MigrationDevelopment Nexus. Evidence and Policy Options. IOM Migration Research Series, n. 8, IOM, 2002.

ØIEN, Cecilie. The Angolan diaspora in Lisbon: An introduction. Economia Global e Gestão, v. 12, n. 3, p. 23-33, 2007.

Organização Internacional para as Migrações - OIM. Angola: A Study of the Impact of Remittances from Portugal and South Africa. Luanda, 2010.

Programa das Nações Unidas para o Desenvolvimento - PNUD. Relatório do Desenvolvimento Humano, Superando barreiras: Mobilidade Humana e Desenvolvimento. 2009. Disponível em: <http://hdr.undp.org/en/media/ HDR_2009_EN_Complete.pdf $>$.

ROBSON, Paul; ROQUE, Sandra (eds.). Aqui na Cidade nada Sobra para Ajudar. Luanda: Development Workshop, 2001.

The Economist. Daily chart. Africa's impressive growth. 2011. Disponível em: <https://www.economist.com/graphic-detail/2011/01/06/africas-impressive-growth>.

Recebido para publicação em 18.07.2018

Aceito para publicação em 01.11.2018

Received for publication in July $18^{\text {th }}, 2018$ Accepted for publication in November 01 ${ }^{\text {st }}, 2018$

ISSN impresso 1980-8585

ISSN eletrônico 2237-9843

http://dx.doi.org/10.1590/1980-85852503880005404 